\title{
Brain ureido degenerative protein modifications are associated with neuroinflammation and proteinopathy in Alzheimer's disease with cerebrovascular disease
}

\author{
Xavier Gallart-Palau, Aida Serra, Benjamin Sian Teck Lee, Xue Guo and Siu Kwan Sze*i)
}

\begin{abstract}
Background: Brain degenerative protein modifications (DPMs) are associated with the apparition and progression of dementia, and at the same time, Alzheimer's disease with cerebrovascular disease (AD + CVD) is the most prevalent form of dementia in the elder population. Thus, understanding the role(s) of brain DPMs in this dementia subtype may provide novel insight on the disease pathogenesis and may aid on the development of novel diagnostic and therapeutic tools. Two essential DPMs known to promote inflammation in several human diseases are the ureido DPMs (uDPMs) arginine citrullination and lysine carbamylation, although they have distinct enzymatic and non-enzymatic origins, respectively. Nevertheless, the implication of uDPMs in the neuropathology of dementia remains poorly understood.

Methods: In this study, we use the state-of-the-art, ultracentrifugation-electrostatic repulsion hydrophilic interaction chromatography (UC-ERLIC)-coupled mass spectrometry technology to undertake a comparative characterization of uDPMs in the soluble and particulate postmortem brain fractions of subjects diagnosed with $A D+C V D$ and age-matched controls.
\end{abstract}

Results: An increase in the formation of uDPMs was observed in all the profiled AD + CVD brains. Citrulline-containing proteins were found more abundant in the soluble fraction of $A D+C V D$ whereas homocitrulline-containing proteins were preferentially abundant in the particulate fraction of AD + CVD brains. Several dementia-specific citrulline residues were also identified in soluble proteins previously categorized as pro-immunogenic, which include the receptor P2X7, alpha-internexin, GFAP, CNP, MBP, and histones. Similarly, diverse dementia-specific homocitrulline residues were also observed in the particulate fractions of $A D+C V D$ in proteins that have been vastly implicated in neuropathology. Intriguingly, we also found that the amino acids immediately flanking arginine residues may specifically influence the increase in protein citrullination.

Conclusions: Taken together, these results indicate that uDPMs widely contribute to the pathophysiology of AD + CVD by promoting neuroinflammation and proteinopathy. Furthermore, the obtained results could help to identify disease-associated proteins that can act as potential targets for therapeutic intervention or as novel biomarkers of specific neuropathology.

Keywords: Deimination, Carbamylation, Proteinopathy, Citrullination, Mixed dementias, Alzheimer's disease

\footnotetext{
* Correspondence: sksze@ntu.edu.sg

Division of Chemical Biology \& BioTechnology, School of Biological Sciences,

Nanyang Technological University, 60 Nanyang Drive, Singapore 637551,

Singapore
} 


\section{Background}

Dementia originates from a range of neurodegenerative and proteinopathic diseases that are predicted to affect over 130 million people worldwide by 2050 [1]. Alzheimer's disease $(\mathrm{AD})$ is the leading cause of this epidemic syndrome, and it accounts for about $60 \%$ of dementia cases [2]. Cerebrovascular disease (CVD) accounts for about $20 \%$ of dementia cases [3] and often coexists with AD in $\mathrm{AD}+\mathrm{CVD}$, a mixed form of dementia that remains as the most prevalent subtype among the elder population [4].

Several protein posttranslational modifications (PTMs) are implicated in the neuropathology of dementia [5] which are also known as degenerative protein modifications (DPMs) [6, 7]. Understanding the role(s) of DPMs is thus expected to provide novel insight on the pathogenesis of these aging-associated diseases, and it may aid on the development of new diagnostic and therapeutic tools. Two of these crucial DPMs that are thought to contribute to the neuropathology of dementia are citrullination and carbamylation [8-10]. Citrullination is an aging-associated DPM $[11,12]$ mediated by peptidylarginine deiminases (PADs), a calcium-dependent family of enzymes that generate the non-coded amino acid citrulline (Cit) from arginine (Arg) residues by hydrolysis [13]. Carbamylation of lysine (Lys) residues oppositely occurs spontaneously using the urea intermediate isocyanic acid as substrate to generate the non-coded amino acid homocitrulline (HCit) [10]. Cit and HCit are almost identical residues and differ only by one carbon in their side chain, although $\mathrm{HCit}$ results from a non-enzymatic chemical reaction and Cit formation is enzymatic [14]. Particularly, both non-coded amino acids are considered as ureido DPMs (uDPMs); hence, they share an ureido group in the side chain [14]. Citrullination is known to cause loss of positive charge in Arg residues, which in turn disturbs the structural order of the protein and makes it more prone to proteolysis [11]. Similarly, carbamylation neutralizes the positively charged Lys residues in an irreversible manner [15] and can result in altered function and pathogenic conformation [16, 17]. Cit and HCit, thus, favor protein denaturation and proteolysis and can also be recognized by the immune system as non-naturally coded amino acids $[6,7,11,18]$. This former fact leads to the apparition of autoimmunity and inflammation, which are at the very basis of several chronic human diseases [19-21].

The neuropathology of dementia, including $\mathrm{AD}+$ CVD, is associated with dysfunctional proteins that form oligomeric structures in the brain parenchyma known as amyloids [6, 22]. Amyloids are resistant to proteolytic degradation and consequently sequestered into inclusion bodies, which are further compartmentalized in the brain parenchyma to reduce toxicity [23-25]. Although the role of protein inclusions appears mainly to be protective [23], chronic accumulation of these structures in the brain is likely to threaten neuronal function and viability [26]. Within the central nervous system (CNS), several DPMs have been associated with the formation and accumulation of amyloids [5] and some studies have suggested an association between citrullination, proteinopathy [27, 28], and brain vascular dysfunction [29, 30]. However, despite the implication that uDPMs might be involved in the neuropathology of AD + CVD, the extent of UDPMs in affected brain cells is unknown and the role(s) of citrullination and carbamylation in the neuropathology of dementia remain far to be fully elucidated [7]. Similarly, although uDPMs are associated with multiple sclerosis (MS) [20] and other autoimmune diseases [21], any apparent nexus between uDPMs and neuroinflammation in AD + CVD has yet to be defined.

The ability to identify and quantify citrullinated and carbamylated proteins in complex samples is essential to understand their role(s) in normal cellular processes and disease states. Though until now, very few uDPMcontaining proteins have been identified and characterized from brain-diseased proteomes [31]. This is mainly due to the chemical and structural similarities that Arg and Lys present with their respective modified counterparts, and between $\mathrm{Cit}$ and $\mathrm{HCit}$, which by the use of classical biochemical methods result in significant cross-reactivity [14, $21,32]$. Recent advances in liquid chromatography mass spectrometry (LC-MS/MS)-based proteomics have made possible the unbiased identification of proteins in complex samples and characterization of isoforms expression, turnover rate, subcellular localization, PTMs, and quantification of altered abundances in disease states [33]. Previously, we have adopted such approaches to characterize neurodegenerative proteomes and other conditions [6, 7, 34]. As part of these studies, we recently developed ultracentrifugationelectrostatic repulsion hydrophilic interaction chromatography (UC-ERLIC)-coupled mass spectrometry to isolate and characterize soluble and aggregated proteins from human brain tissues [35]. Here, we have used this approach to undertake a comparative characterization of uDPMs in the soluble and aggregated postmortem brain proteomes of $\mathrm{AD}$ + CVD and age-matched controls. Our results show the novel identification of relevant dementia-specific citrullinated and carbamylated brain proteins. This study thus provides new insight into the implications of uDPMs in the neuropathology of $\mathrm{AD}+\mathrm{CVD}$ and will pave the way for further investigations on uDPMs as potential targets for therapeutic intervention or disease-state biomarkers in this fatal dementia subtype.

\section{Methods}

Chemicals and reagents

All the reagents used in this study were purchased from Sigma-Aldrich (St. Louis, MO, USA) unless otherwise 
specified. Protease inhibitor cocktail tablets were purchased from Roche (Basel, Switzerland), and sequencinggrade-modified trypsin was purchased from Promega (Madison, WI, USA).

\section{Postmortem brain tissues}

$\mathrm{AD}+\mathrm{CVD}$ and healthy age-matched control (Ctrl) autopsied human brain tissues (middle temporal lobe, BA21 region) were generously donated by the Harvard Brain Tissue Resource Center (HBTRC, Boston, MA, USA). All patients met clinical diagnosis for dementia and histological criteria for AD + CVD (mixed dementias) at the time of autopsy. The available details of the samples, which include age, postmortem delay, and gender can be found in Additional file 1: Table S1. Three biological replicates were independently analyzed in this study for each experimental condition (soluble and particulate proteomes). Brain tissues were stored in liquid nitrogen from the time of autopsy and subsequently kept at $-150{ }^{\circ} \mathrm{C}$ until use. BA21 brain region was dissected, meninges were removed, and $\sim 100 \mathrm{mg}$ of tissue from each subject were washed thrice during $10 \mathrm{~min}$ in $1 \mathrm{X}$ PBS.

\section{Homogenization of postmortem brain tissues}

Dissected brain tissues were homogenized as previously described [36], and all the following described procedures on postmortem tissues were performed on ice. Brain tissues were suspended in $250 \mu \mathrm{L}$ of homogenization buffer $(0.5 \%(w / v)$ sodium deoxycholate (SDC) in $100 \mathrm{mM}$ ammonium acetate (AA) (pH 6.0) or $1 \%(w / v) ~ N$-lauroylsarcosine in $30 \mathrm{mM}$ Tris- $\mathrm{HCl}(\mathrm{pH} 7.4)$ and $150 \mathrm{mM} \mathrm{NaCl}$ and were supplemented with protease inhibitor cocktail. Approximately, $100 \mathrm{mg}$ of previously washed metallic beads $(0.9-2.0-\mathrm{mm}$ particles) were added to each safelock tube that contained the tissues and homogenization buffer. Homogenization was then performed using the bullet blender homogenizer (Next Advance, NY, USA) at high intensity during $5 \mathrm{~min}$ at $4{ }^{\circ} \mathrm{C}$. The tissue homogenates were subsequently centrifuged at $10,000 \times g, 4{ }^{\circ} \mathrm{C}$, for $10 \mathrm{~min}$, and the supernatants were collected. Remaining pellets were subject to further rounds of homogenization till the pellet was not observable. The obtained supernatants from each round of homogenization were finally combined and briefly vortexed.

\section{Isolation of the soluble and particulate brain proteomes by UC-ERLIC}

Soluble and particulate brain proteomes were isolated from brain homogenates by ultracentrifugation-electrostatic repulsion hydrophilic interaction chromatography (UCERLIC)-coupled mass spectrometry-based proteomics as we recently reported [35], although with minor modifications in this study. Soluble homogenates were centrifuged at $3000 \times g, 4{ }^{\circ} \mathrm{C}$, during $10 \mathrm{~min}$ to remove cell debris. Supernatants were then subjected to ultracentrifugation at $112,000 \times g, 4{ }^{\circ} \mathrm{C}$, during $60 \mathrm{~min}$, transferred to a new tube, and subjected to two further rounds of ultracentrifugation under the same conditions. Supernatants obtained from each round of ultracentrifugation were combined and transferred to new tubes (soluble fraction). The generated particulate pellets from the last two ultracentrifugation rounds were re-solubilized in $150 \mu \mathrm{L}$ of $5 \% \mathrm{SDC}(w / v)$ in $100 \mathrm{mM} \mathrm{AA}$ or $3 \%$ sodium dodecyl sulfate (SDS) in $1 \mathrm{X}$ PBS when the sample was homogenized in sarcosyl and combined to obtain the final particulate proteome.

\section{In-solution tryptic digestion of human brain proteins}

Soluble and particulate proteomes were subject to insolution tryptic digestion as previously described [37]. Briefly, $0.5 \mathrm{mg}$ of proteins from each sample and condition previously quantified by bicinchoninic acid protein assay (BCA) were reduced with $10 \mathrm{mM}$ dithiothreitol (DTT) at $60{ }^{\circ} \mathrm{C}$ during $30 \mathrm{~min}$. Proteins were alkylated with $20 \mathrm{mM}$ iodoacetamide at room temperature protected from the light during $45 \mathrm{~min}$. Subsequently, the samples were diluted 10-fold with $100 \mathrm{mM}$ AA containing $10 \mathrm{mM}$ DTT and incubated at $37^{\circ} \mathrm{C}$ for $30 \mathrm{~min}$. Digestion was performed at $30{ }^{\circ} \mathrm{C}$ overnight at $1: 20(w / w)$ enzymeto-substrate ratio using sequencing-grade-modified trypsin. Enzymatic digestion was quenched by addition of $0.5 \%$ formic acid (FA). SDC under acidic conditions was pelleted by centrifugation at $12,000 \times g, 4{ }^{\circ} \mathrm{C}$, for $10 \mathrm{~min}$ as previously indicated [37]. The supernatant containing tryptic-digested peptides was then collected, and the SDC pellet was re-suspended in $0.5 \%$ ammonium hydroxide for further peptide recovery. SDC was again precipitated by the addition of $0.5 \% \mathrm{FA}$ and pelleted by centrifugation at $12,000 \times g, 4{ }^{\circ} \mathrm{C}$, for $10 \mathrm{~min}$. After centrifugation, the supernatant was collected. Recovery of peptides from the SDC pellet was performed thrice. All the supernatants were combined together. Tryptic-digested peptides were desalted using a C-18 Sep-pack 1 g cartridge (Waters, Milford, MA, USA). Elution was performed with $1 \mathrm{~mL}$ of $75 \%$ acetonitrile (ACN), 0.1\% FA buffer. The eluted peptides were then dried using a vacuum concentrator (Eppendorf, Hamburg, Germany) and reconstituted for HPLC fractionation with $200 \mu \mathrm{L}$ of $80 \% \mathrm{ACN}, 0.1 \%$ acetic acid.

\section{In-gel digestion of human brain proteins}

SDS-solubilized proteins from the sarcosyl particulate fractions were resolved in a $12 \%$ SDS-PAGE gel. PAGE gel was stained using coomassie brilliant blue, and protein lanes were divided in 12 main areas according to the observed protein intensities. Gel lanes were cut into approximately $1-\mathrm{mm}^{2}$ cubes and washed with $25 \mathrm{mM}$ ammonium bicarbonate (ABB) in 50\% ACN. Peptides 
contained in distained gel pieces were reduced in $10 \mathrm{mM}$ DTT in $25 \mathrm{mM} \mathrm{ABB}$ at $60{ }^{\circ} \mathrm{C}$ for $1 \mathrm{~h}$ and subsequently alkylated in $55 \mathrm{mM}$ IAA in $25 \mathrm{mM} \mathrm{ABB}$ at room temperature for $45 \mathrm{~min}$ in the dark. The gel cubes were then dehydrated in $100 \% \mathrm{ACN}$ in two washes for $1 \mathrm{~min}$ each and dried in the speedvac for $5 \mathrm{~min}$ at $30{ }^{\circ} \mathrm{C}$. Tryptic digestion of proteins was performed overnight at $37^{\circ} \mathrm{C}$ by the addition of $10 \mathrm{ng} / \mu \mathrm{l}$ of sequencing-grademodified trypsin (prepared in $25 \mathrm{mM} \mathrm{ABB}$ buffer). Tryptic-digested peptides were extracted from the gel cubes with $50 \% \mathrm{ACN}$ and $5 \%$ acetic acid by vigorous vortexing during $30 \mathrm{~min}$. The extraction step was repeated four times, and the obtained supernatants were combined and dried in the speedvac. The dried peptides were then re-suspended in 3\% ACN, $0.1 \% \mathrm{FA}$, for subsequent LC-MS/MS analysis.

\section{High-pressure liquid chromatography fractionation}

Reconstituted tryptic peptides after in-solution digestion were fractionated by a PolyWAX column $(4.6 \times 200 \mathrm{~mm}$, $3 \mu \mathrm{m}$, PolyLC, Columbia, MD, USA) using a Shimadzu Prominence UFLC system (Kyoto, Japan). Peptide intensities were monitored at $280 \mathrm{~nm}$. Peptides were separated in a 72-min gradient using $80 \% \mathrm{ACN}, 0.1 \%$ acetic acid, as mobile phase $\mathrm{A}$, and $10 \% \mathrm{ACN}, 0.1 \% \mathrm{FA}$, as mobile phase $\mathrm{B}$. Separation of peptides was carried out in a 60-min gradient at a flow rate of $1 \mathrm{ml} / \mathrm{min}$ as follows: $0 \%$ for $5 \mathrm{~min}, 0-20 \%$ B for $25 \mathrm{~min}, 20-33 \%$ B for $10 \mathrm{~min}, 33-60 \%$ B for $10 \mathrm{~min}$, and $60-100 \%$ B for $5 \mathrm{~min}$, followed by $10 \mathrm{~min}$ at $100 \% \mathrm{~B}$. Fractions were collected every minute, partially dried in a vacuum concentrator to reduce the volume, and pooled according to peak intensities. Combined fractions were dried completely and reconstituted in $3 \% \mathrm{ACN}, 0.1 \%$ FA.

\section{Liquid chromatography mass spectrometry analysis}

Analysis of peptides was performed using an Orbitrap Elite mass spectrometer coupled with a Dionex UltiMate 3000 UHPLC system from Thermo Fisher Scientific Inc. (Bremen, Germany). Approximately, $2 \mu \mathrm{g}$ of peptides were injected into a reverse phase Acclaim PepMap RSL column $(75 \mu \mathrm{m}$ ID $\times 15 \mathrm{~cm}, 2-\mu \mathrm{m}$ particle size, Thermo Fisher Scientific Inc.) maintained at $35{ }^{\circ} \mathrm{C}$ and using a flow rate of $0.3 \mu \mathrm{L} / \mathrm{min}$. Peptides were separated in a 60 min gradient using $0.1 \% \mathrm{FA}$ as mobile phase $\mathrm{A}$ and $90 \%$ ACN, 0.1\% FA, as mobile phase B. The gradient used for the separation of peptides was as follows: starting at $3 \%$ mobile phase B for $1 \mathrm{~min}, 3-35 \%$ mobile phase B over $47 \mathrm{~min}, 35-50 \%$ mobile phase B over $4 \mathrm{~min}$, and $50-$ $80 \%$ mobile phase B in $6 \mathrm{~s}$ and maintained isocratic for $78 \mathrm{~s}$. Then, reverted to initial conditions over $6 \mathrm{~s}$ and maintained isocratic for $6.5 \mathrm{~min}$. Tryptic-digested peptides were sprayed using a Bruker-Michrom Inc. Michrom's Thermo Captive Spray nanoelectrospray ion source (Bruker-Michrom Inc., Auburn, CA, USA) with
$1.5 \mathrm{kV}$ spray voltage. Orbitrap Elite mass spectrometer was set to positive mode for data acquisition using Xcalibur 2.2 SP1.48 software (Thermo Fisher Scientific Inc., Bremen, Germany). Data acquisition was performed by alternating between full Fourier transform-mass spectrometry (FT-MS; 350-2000 $\mathrm{m} / \mathrm{z}$, resolution 60,000, $1 \mu$ scan per spectrum) and FT-MS/MS (150-2000 m/z, resolution 30,000, 1 sscan per spectrum) for the ten most intense ions above 500 count threshold with charge $>+2$. Fragmentation was performed using highenergy collisional dissociation (HCD) mode with $32 \%$ normalized collision energy. Automatic gain control values for FT-MS and FT-MS/MS were set at $1 \times 10^{6}$.

\section{Bioinformatics and data analysis}

LC-MS/MS data was searched in PEAKS Studio version 7.5 [38] (Bioinformatics Solutions, Waterloo, Canada). Precursor ion tolerance and fragment ion tolerance were kept during the database search at $10 \mathrm{ppm}$ and $0.05 \mathrm{Da}$, respectively. Trypsin with non-specific cleavage on both ends of the peptide was allowed. Carbamidomethylation of cysteine residues was considered as fixed modification. The PEAKS PTM algorithm [39] was used to identify the presence of uDPMs in the brain proteomes. False discovery rate was kept as default by the software, and decoy-target identification of the peptides was performed. To extract the most abundant peptides from the particulate brain proteomes, only those peptides with relative signal intensities higher or equal to $10^{8}$ were considered. This restrictive criterion allowed for the unique consideration of the most confidently identified peptides. The mean signal intensity was calculated individually for every subject and experimental condition (soluble and particulate brain proteomes) and contributed to the calculation of the grand mean signal intensity for each group, which has been reported here.

Enrichment distribution of the AD + CVD particulate brain proteomes was analyzed using the enrichment analysis software FunRich [40] as described [41]. The absolute number of unique proteins with identified citrullinated (Arg) and carbamylated (Lys) residues was included in this analysis. To analyze the aggregation pattern of the identified neuroinflammatory markers in AD + CVD only the proteins that were consistently identified in at least two individuals of the same group were considered. Student's $t$ test was performed to establish statistical significance between experimental groups $(p<0.05)$. All statistical analyses and graphs were performed and plotted in GraphPad Prism v6.01 (La Jolla, CA, USA). The bioinformatics study of the biochemical composition of hypercitrullinated proteins in the brain proteome of $\mathrm{AD}+\mathrm{CVD}$ was performed using an in-house-created macro for Microsoft Excel. All the possible citrulline triplets were screened in this analysis resulting in a total of 400 combinations as shown in 
Additional file 2: Dataset 1. The total signal intensity for every group of peptides triplet was then ranked from the highest to lowest. Only those top five triplets that were consistently identified as hypercitrullinated in all subjects and conditions are reported. Data is reported as mean \pm standard deviation (SD).

\section{Results}

\section{Composition of brain amyloids in AD + CVD}

Sarcosyl can be considered as a gold standard detergent for biochemical characterization of insoluble aggregates from brain tissues [42, 43]. However, the use of this detergent has to be coupled to in-gel digestion. To characterize the molecular composition of brain amyloids, we proposed the use of sodium deoxycholate (SDC), a detergent that allowed in-solution digestion and multidimensional chromatography, to improve the identification of posttranslationally modified peptides [37]. For confirmatory purposes, we performed a comparative study to analyze the performance of both partitioning methodologies. No substantial differences were observed on the total amount of amyloidal protein obtained by sarcosyl and SDC in BCA assays $(1.91 \mathrm{mg}$ vs. $1.94 \mathrm{mg}$, respectively). Similarly, no obvious differences were observed on the total number of proteins identified by LC-MS/MS from both methodologies (Additional file 3: Figure S1a and Additional file 4: Dataset 2), although as expected, the SDC condition increased by near $50 \%$ the identification of unique uDPM-containing peptides (Additional file 3: Figure S1b).

A similar number of proteins were identified by UCERLIC in the particulate proteomes of age-matched controls and AD + CVD (Additional file 5: Dataset 3). However, careful analysis of the most abundant peptides has shown apparently higher accumulation of dysfunctional proteins in the particulate proteomes of the dementia brains (Fig. 1a). Screening of those particulate proteins uniquely found in AD + CVD revealed cell communication (synaptic proteins) and energy production (mitochondrial proteins) as the two most abundant protein categories that become aggregated in these tissues (Fig. 1b). Cell maintenance and immune response though were also found in that analysis as meaningful abundant protein categories in the particulate proteomes of $\mathrm{AD}+$ CVD (Fig. 1b). In particular, immune response-related proteins represent near the $5 \%$ of the total unique aggregated proteins in $A D+C V D$ brains (Fig. 1b).

\section{uDPMs and brain proteinopathy}

An increase in the formation of Cit and HCit residues was observed in the brains of $\mathrm{AD}+\mathrm{CVD}$ compared to those of age-matched controls (Fig. 1c, e). Nevertheless, higher amount of Cit residues was uniquely observed in the soluble brain fractions of dementia brains (Fig. 1c).
Analysis of unmodified proteins prone to contain Cit residues also indicated a relative increase of these proteins in the soluble brain proteomes of AD + CVD (Fig. 1d). Contrary, higher amount of $\mathrm{HCit}$ residues was uniquely observed in the particulate fractions of dementia brains (Fig. 1e). No significant differences were observed on the aggregation pattern of the unmodified proteins prone to contain HCit residues (Fig. 1f). However, sequestration of unmodified proteins prone to contain Cit residues to the particulate brain fraction was a meaningful phenomenon apparently characteristic of non-demented brains (Fig. 1d).

We then investigated group-specific uDPMs, considering uniquely those modified residues that are consistently modified in at least two individuals of the same group and that at the same time were not identified in the same experimental condition (soluble and particulate) in any individual of the other group. A total of seven specific HCit residues were confidently identified in the particulate fraction in this screening (Table 1). These dementia-specific HCit-containing proteins include brain acid soluble protein 1 (BASP1), spectrin alpha chain 1 (SPTAN1), and glial fibrillary acidic protein (GFAP) (Table 1). Stoichiometric analysis of dementia-specific HCit residues revealed that the frequency of modification of Lys residues exceeded the $50 \%$ in the majority of these proteins (Table 1). The whole list of homocitrulline sites identified in the particulate brain proteomes of $A D+C V D$ is included in Additional file 6: Dataset 4.

\section{Citrullination and neuroinflammation}

Several brain proteins that have been vastly implicated in autoimmunity and pro-inflammatory processes in a wide range of human diseases were identified in this study as containing dementia-specific pro-immunogenic Cit sites in the soluble brain proteome of $\mathrm{AD}+\mathrm{CVD}$ subjects (Table 2). Stoichiometric analysis of these pro-immunogenic sites indicated that the frequency of modification of Arg residues was $100 \%$ for the vast majority of the specific sites identified (Table 2). The list of dementia-specific Cit sites that were identified in the soluble fraction of $A D+C V D$ brains is shown in Additional file 7: Dataset 5. Of note, this list shows the identification of several histone molecules which contain Cit sites while being present in soluble form in the brain of dementia patients. The complete list of all identified soluble $\mathrm{AD}+\mathrm{CVD}$ Cit sites, including those residues that are nondementia specific is listed in Additional file 8: Dataset 6.

Since apparently higher accumulation of unmodified proteins that are prone to contain Cit residues into the particulate fraction was observed in the brain of agematched controls, we also scrutinized which AD + CVD citrulline residues become consistently aggregated in age-matched controls and remain soluble in the brain of dementia subjects during $\mathrm{AD}+\mathrm{CVD}$. We found that the 

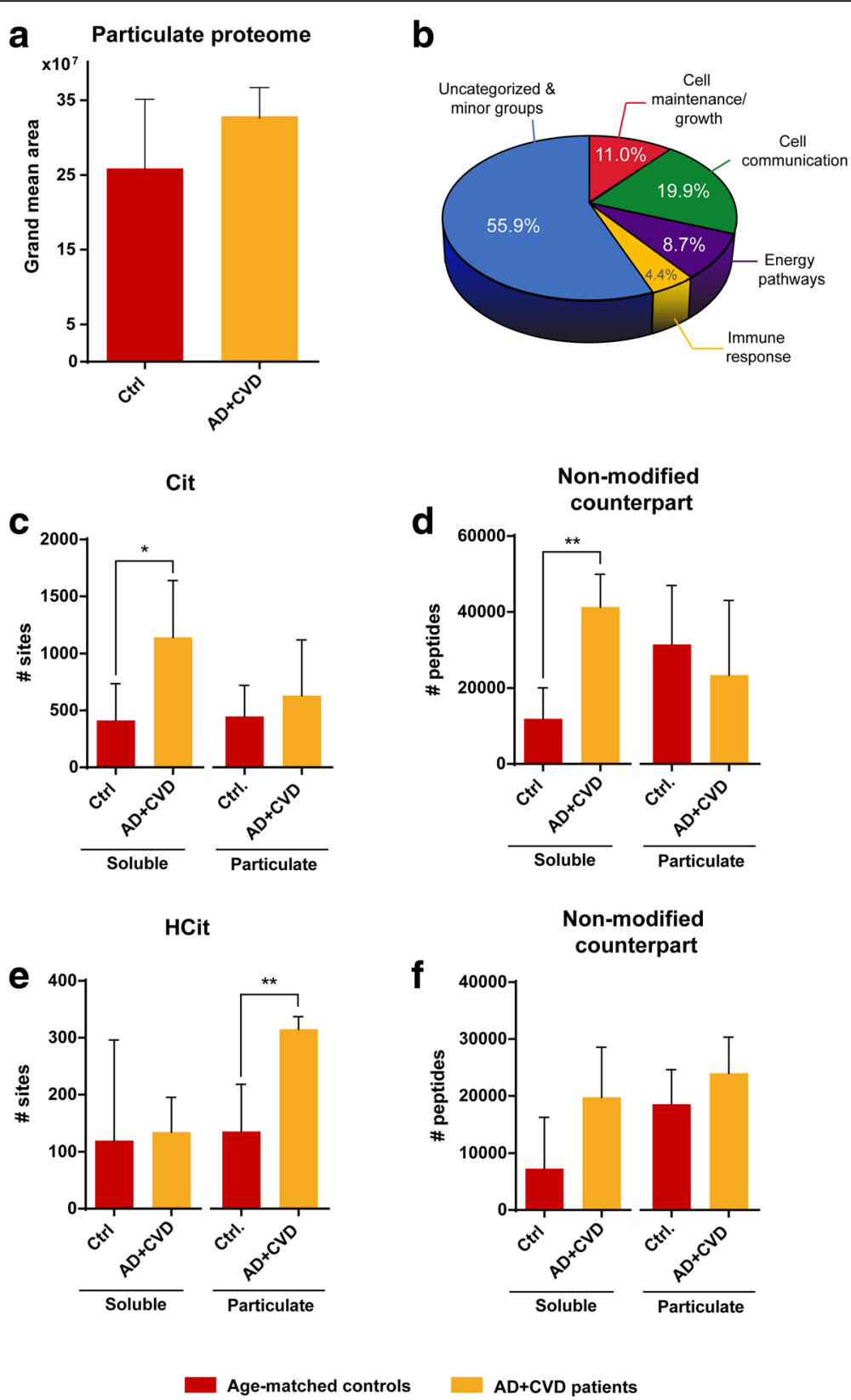

Fig. 1 Profiling of the soluble and particulate brain proteomes in AD + CVD. $\mathbf{a}$ Grand mean ion intensity of the most abundant peptides from the $A D+C V D$ and age-matched control particulate proteomes. $\mathbf{b}$ Enrichment analysis of the dementia-specific proteins identified in the particulate proteomes of AD + CVD. c Distribution of citrulline sites in the soluble and particulate proteomes of AD + CVD and age-matched controls. $\mathbf{d}$ Distribution of citrulline non-modified counterpart peptides in the soluble and particulate proteomes of AD + CVD and age-matched controls. e Distribution of homocitrulline sites in the soluble and particulate proteomes of AD + CVD and age-matched controls. $\mathbf{f}$ Distribution of homocitrulline non-modified counterpart peptides in the soluble and particulate proteomes of AD + CVD and age-matched controls. Data is reported as mean + SD $\left({ }^{*} p<0.05\right.$ one-tailed Student's $t$ test. ${ }^{* *} p<0.05$ two-tailed Student's $t$ test)

citrulline residue 213 (SHGR"TQDENPVVHFF) of myelin basic protein (MBP), citrulline residues 24 (KVFG DGSR"LSAR) and 83 (RRPPASDGLDLSQAAAR"TNEY K) of alpha-internexin, and the citrulline residue 83 (IIPR"HLQLAIRNDEELNK) of histone H2AX were successfully identified in this analysis.
Soluble hypercitrullinated proteins are associated with enhanced autoimmunity and consequent neuroinflammation, and to further explore this hypothesis in AD + CVD, we evaluated the pattern of aggregation of the identified neuroinflammatory markers from all the profiled brain tissues. We observed that the protein complement factor-5, 
Table 1 List of proteins that contain exclusive HCit residues in the particulate brain proteome of AD + CVD

\begin{tabular}{|c|c|c|c|c|c|}
\hline Gene & Protein & Peptide & Protein residue ${ }^{b}$ & $\begin{array}{l}\text { Secondary } \\
\text { Structure }^{c}\end{array}$ & Stoichiometry $^{d}$ \\
\hline SPTAN1 & Spectrin alpha chain non-erythrocytic 1 & Ka HQLLEADISAHEDR & 1699 & - & 50 \\
\hline ATP1A3 & Sodium/potassium-transporting ATPase subunit alpha-3 & KaADIGVAMGIAGSDVSK & 717 & - & 16 \\
\hline ACTB & Actin cytoplasmic 1 & NSIMK ${ }^{\mathrm{a}} C D V D I R$ & 284 & - & 67 \\
\hline ATP6V0A1 & V-type proton ATPase $116 \mathrm{kDa}$ subunit a & $K^{\mathrm{a} A N I P I M D T G E N P E V P F P R}$ & 74 & - & 22 \\
\hline ATP2B4 & Plasma membrane calcium-transporting ATPase 4 & $K^{a}$ ADVGFAMGIAGTDVAK & 795 & - & 41 \\
\hline BASP1 & Brain acid soluble protein 1 & $K^{\mathrm{a} T E A P A A P A A Q E T K}$ & 150 & - & 50 \\
\hline GFAP & Glial fibrillary acidic protein & SK FADLTDAAAR & 260 & Coil 2B & 55 \\
\hline
\end{tabular}

${ }^{a}$ The homocitrulline residue in the identified peptide

${ }^{\mathrm{b}}$ The residue number in the protein sequence

'When available, the location of the HCit residue in the secondary structure of the protein

${ }^{d}$ The stoichiometric ratio (percentage of occurrence) of HCit from the total peptides identified that contain the Lys site in the protein (unmodified + modified)

an essential member of the membrane attack complex (MAC), was the unique neuroinflammatory marker found in association with Cit residues in the soluble brain fraction of AD + CVD subjects (Fig. 2a).

\section{Biochemical characterization of increased citrullination in the brain proteome}

In order to elucidate if enzymatic citrullination of susceptible brain proteins is a randomized calcium-dependent process or conversely it proceeds by any organized and specific biochemical pattern, we scrutinized here the identified amino acid triplets that surround citrulline residues in all the profiled brain proteomes. We strikingly observed that the most abundant citrullinated Arg residues were commonly surrounded by either the small amino acid alanine (Ala) or the aromatic amino acids proline (Pro) and histidine (His) as shown in Fig. 2b.

\section{Discussion}

Unbiased profiling of the soluble and particulate brain proteomes confirmed that formation of amyloids in the brain parenchyma is an aging-associated process that takes place with independence of the apparition of dementia symptoms. Higher accumulation of proteins was though observed in the brains of dementia subjects. These findings were consistent with previous reports showing that there is basal amyloid formation in the brain parenchyma of aged subjects [44] and higher accumulation of dysfunctional proteins in brain tissues undergoing neurodegeneration $[35,45]$. Detailed analysis of the particulate proteomes has shown immune response-related proteins as a protein category that becomes preferentially aggregated in the temporal lobe of dementia subjects. Although neuroinflammation is considered a factor that plays a causal role in the development of dementia [46, 47], the existing links between proteinopathy and neuroinflammation in this progressive and fatal disease remain poorly understood [48].
Increase in uDPMs, as identified in dementia brains, suggests activation of a defective immune and proinflammatory response [48]. uDPMs are associated with apparition of inflammation and proteinopathy; however, only very few proteins that might mediate these pathogenic outcomes in dementia have been until now identified $[27,28]$. We previously reported that an increase in citrullination in certain MBP residues did not apparently influence the aggregation ability of the protein [49]. Here, we globally confirm this finding as citrullinated proteins tended to remain soluble in the temporal lobe of $\mathrm{AD}+\mathrm{CVD}$ subjects. In further detail, we found that the purinergic receptor P2X7 was modified by a dementia-specific Cit residue in the soluble brain proteome of AD + CVD. To the best of our knowledge, this is the first time that this crucial immune receptor appears modified by PADs in a dementia-relevant manner. Activation of the immune response in the brain is an ATPdependent process initiated by injury and death of the surrounding cells $[50,51]$ and mediated by P2X7 in microglia [52-54], a receptor that also induces increase in citrullination and release of Cit residues out of the cell [55]. Similarly, several dementia-specific Cit sites were identified in histones $\mathrm{H} 2$ and $\mathrm{H} 4$ in the soluble brain fractions, which suggests ongoing formation of neurotrophil extracellular traps (NETs). NETs have been proven as molecular culprits in the pathogenesis of rheumatoid arthritis (RA) and other autoimmune diseases [56-59]. Formation of NETs is mediated by citrullination of histones, which neutralizes the charge of these molecules promoting chromatin decondensation [60]. Besides, the following proteins CNP, GFAP, Alphainternexin, Hexokinase-1, Neurofilament Light Polypeptide, Adduccin-1, Reticulon-3, Adenylate kinase isoenzyme 1, Transgelin-3 Synaptotagmin-7, Stathmin, P2X purinoceptor 7, Heat shock protein HSP 90-alpha, Neuromodulin, MBP, and Cortactin were also identified containing dementia-specific Cit residues in the soluble brain proteome of $\mathrm{AD}+\mathrm{CVD}$. Considerably, all these 
Table 2 List of proinflammatory and immunogenic proteins that contain exclusive Cit residues in the soluble brain proteome of AD + CVD. The proteins listed in this table have been previously implicated in inflammatory and autoimmune processes (reference(s) column)

\begin{tabular}{|c|c|c|c|c|c|c|}
\hline Gene & Protein & Reference(s) & Peptide(s) & $\begin{array}{l}\text { Protein } \\
\text { residue(s) }\end{array}$ & Location & $\begin{array}{l}\text { Stoicho- } \\
\text { metry }^{\mathrm{a}}\end{array}$ \\
\hline$\overline{C N P}$ & $\begin{array}{l}\text { 2' 3'-cyclic-nucleotide } \\
\text { 3'-phosp. }\end{array}$ & Birnbaum et al. 1996 [61] & ELR ${ }^{\mathrm{b}}$ QFVPGDEPR & 224 & $\begin{array}{l}\text { Helix (223- } \\
226)\end{array}$ & 100 \\
\hline GFAP & $\begin{array}{l}\text { Glial fibrillary acidic } \\
\text { protein }\end{array}$ & Sasaki et al. 2014 [62] & SNLQIR ETSLDTK & 390 & $\begin{array}{l}\text { Tail (378- } \\
432)\end{array}$ & 100 \\
\hline \multirow[t]{2}{*}{ INA } & \multirow[t]{2}{*}{ Alpha-internexin } & \multirow[t]{2}{*}{ Lu et al. 2010 [63] } & RRPPASDGLDLSQAAAR ${ }^{\mathrm{b}} \mathrm{TNEYK}$ & 83 & Head (1-87) & 56 \\
\hline & & & KVFGDGSR $R^{\mathrm{b}} \mathrm{LSAR}$ & 28 & Head (1-87) & 100 \\
\hline \multirow[t]{2}{*}{ HK1 } & \multirow[t]{2}{*}{ Hexokinase-1 } & \multirow[t]{2}{*}{ Norman et al. 2015 [64] } & ITPELLTR ${ }^{\mathrm{b}} \mathrm{GK}$ & 331 & N/A & 100 \\
\hline & & & NGLSR DFNPTATVK & 53 & Turn (53-55) & 100 \\
\hline NEFL & $\begin{array}{l}\text { Neurofilament light } \\
\text { polypeptide }\end{array}$ & Jain et al. 2009 [65] & WETPR ${ }^{b}$ VHISS & 23 & Head (2-92) & 100 \\
\hline ADD1 & Adducin 1 (Alpha) & Rötzer et al. 2014 [66] & EDGHR ${ }^{\mathrm{b}} T S T S A V P N L F V P L N T N P K$ & 479 & - & 67 \\
\hline RTN3 & Reticulon-3 & Chiurchiù et al. 2014 [67] & TQIDHYVGIAR DQTK & 1009 & - & 100 \\
\hline AK1 & $\begin{array}{l}\text { Adenylate kinase } \\
\text { isoenzyme } 1\end{array}$ & Tüzün et al. 2007 [68] & YGYTHLSTGDLLR ${ }^{\mathrm{b}}$ SEVSSGSAR & 44 & $\begin{array}{l}\text { Helix (39- } \\
48)\end{array}$ & 100 \\
\hline TAGL3 & Transgelin-3 & Na et al. 2015 [69] & $R^{b} G F S E E Q L R$ & 160 & - & 100 \\
\hline SYT7 & Synaptotagmin-7 & Chakrabarti et al. 2003 [70] & YKNSLETVGTPDSGR ${ }^{\mathrm{b}} \mathrm{GR}$ & 63 & - & 100 \\
\hline STMN1 & Stathmin & Bsibsi et al. 2010 [71] & $\mathrm{R}^{\mathrm{b}} \mathrm{ASGQAFELILSPR}$ & 14 & - & 71 \\
\hline $\mathrm{P} 2 \mathrm{RX} 7$ & P2X purinoceptor 7 & Lister et al. 2007 [52] & LPLALHDTPPIPGQPEEIQLLR ${ }^{b} \mathrm{~K}$ & 463 & - & 57 \\
\hline HSP90AA1 & $\begin{array}{l}\text { Heat shock protein } \\
\text { HSP 90-alpha }\end{array}$ & Tukaj et al. 2016 [72] & GWDSEDLPLNISR ${ }^{\mathrm{b}}$ EMLQQSK & 400 & - & 40 \\
\hline NEUM & Neuromodulin & Hung et al. 2016 [73] & IQASFR' GHITR & 43 & - & 100 \\
\hline \multirow[t]{6}{*}{ MBP } & \multirow[t]{6}{*}{ Myelin basic protein } & \multirow[t]{6}{*}{ Zierath et al. 2015 [74] } & FGYGGR ${ }^{\mathrm{b}}$ ASDYK & 64 & - & 45 \\
\hline & & & SHGR'TQDENPWHFF & $213^{c}$ & $\begin{array}{l}\text { EAE (179- } \\
222)\end{array}$ & 41 \\
\hline & & & HGFLPR ${ }^{\mathrm{b}} H R D T G I L D S I G R$ & 165 & - & 32 \\
\hline & & & FFGGDR ${ }^{\mathrm{b}}$ GAPKR & $183^{\mathrm{C}}$ & $\begin{array}{l}\text { EAE (179- } \\
\text { 222) }\end{array}$ & 75 \\
\hline & & & YLATASTMDHAR ${ }^{\mathrm{b}} \mathrm{HG}$ & 159 & - & 58 \\
\hline & & & FSWGAEGQRPGFGYGGR ${ }^{\mathrm{b}}$ ASDYKSAHK & 264 & - & 45 \\
\hline CTTN & Src substrate cortactin & $\begin{array}{l}\text { Labrador-Horrillo et al. } 2014 \\
\text { [75] }\end{array}$ & HCSQVDSVR ${ }^{\mathrm{b}}$ GFGGK & 119 & - & 100 \\
\hline
\end{tabular}

${ }^{\mathrm{b}}$ Indicates the citrulline residues in the identified peptides

Indicates the MBP citrulline residues in mice that were identified in the protein homolog region that induces experimental autoimmune encephalomyelitis (EAE)

andicates the stoichiometric ratio (percentage of occurrence) of Cit from the total peptides identified that contain the Arg site in the protein (unmodified

+ modified)

modified proteins have been previously implicated in autoimmunity and inflammation in several human diseases [61-75], though many of them were not previously identified in the sphere of dementia. An increase in citrulline in soluble brain fractions was associated with the increase of the MAC protein complement factor-5 in $\mathrm{AD}+\mathrm{CVD}$, the unique neuroinflammatory marker found upregulated in the soluble fraction of dementia subjects compared to age-matched controls. We also observed that an increase in citrullination in $A D+C V D$ brains was favored by the small amino acid Ala and the aromatic amino acids Pro and His at the flank of Arg residues. The biochemical patterns that influence aberrant citrullination in dementia hold great promise in the search for novel pharmacological targets to fight chronic neuroinflammation in this disease.

Our main aim for this study was also to understand how uDPMs can influence the aggregation ability of temporal lobe proteome in AD + CVD. We observed that HCit, a spontaneous non-enzymatic aging-associated uDPM that becomes hardly distinguishable from Cit by conventional biochemical methods [14, 32, 76], seems to clearly contribute to brain proteinopathy in this dementia subtype. The observed enrichment of HCit dementia- 


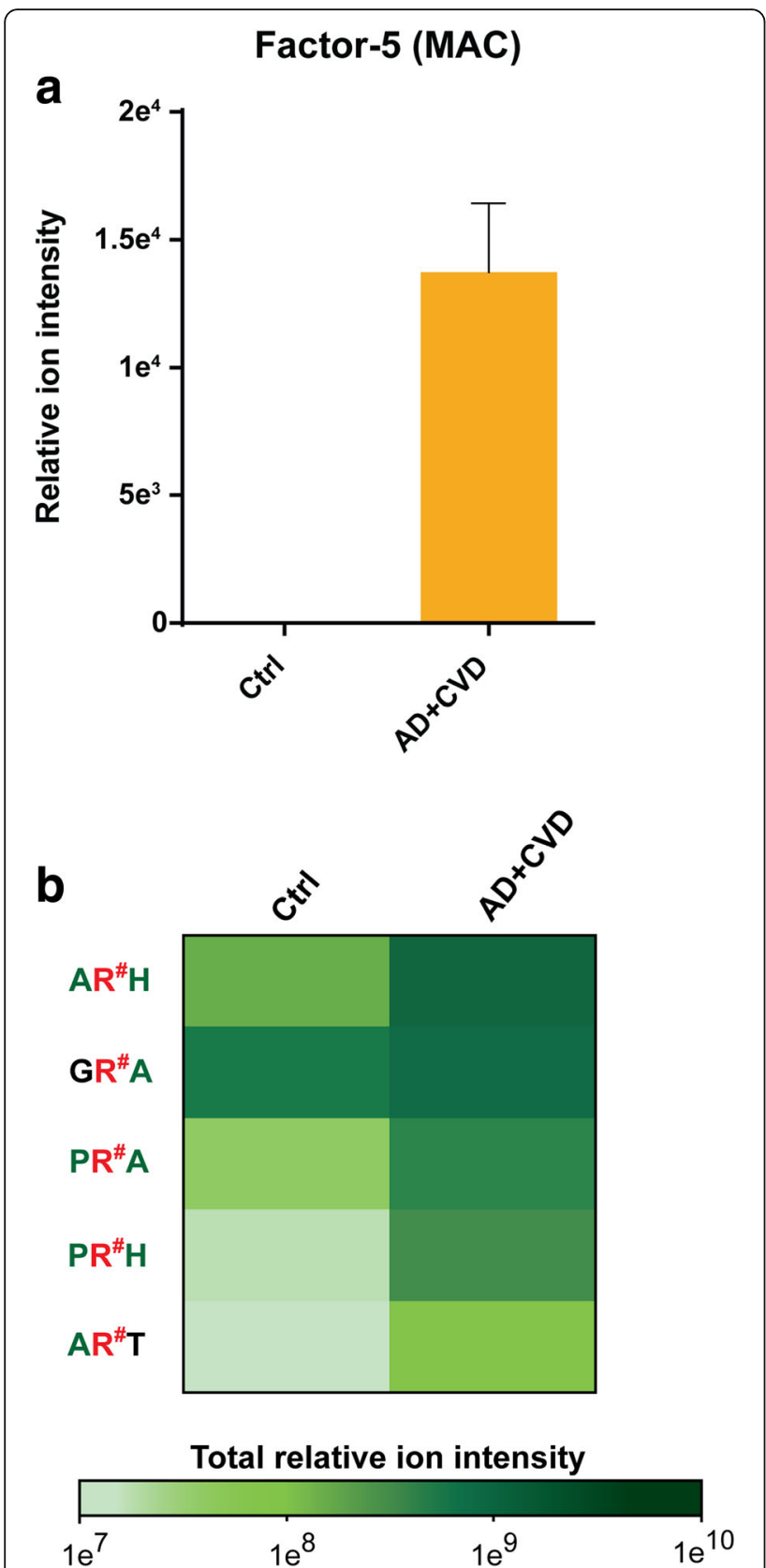

Fig. 2 Citrullination and neuroinflammation in the brain proteome of $A D+C V D$. a MS precursor ion intensity of the neuroinflammatory marker complement- 5 core member of the membrane attack response. This marker was only identified in soluble form in the brain proteomes of $A D+C V D$, and it was the unique neuroinflammatory marker identified in association with the observed aggregation pattern of Cit residues. b Heatmap showing the levels of the top five most intense Cit amino acid triplets in the brain proteome of AD + CVD and age-matched controls. The small residue alanine (Ala) and the aromatic residues proline (Pro) and histidine (His) are commonly found at the flanks of Cit residues in the most abundant citrullinated peptides of the brain proteome. The column of the amino acid triplets in green color indicates the common top five amino acids and in black color, the uncommon amino acids specific sites into the particulate fraction of $A D+C V D$ brains may indicate involvement of HCit in early brain inflammatory processes. Mydel and colleagues demonstrated that HCit triggered early activation of proinflammatory cells, which was the primary step to recognition of Cit residues in autoimmune inflammation [77]. Besides, Currais and colleagues [78] recently suggested that certain proteins from the particulate brain fraction may contribute to the progression of neuroinflammation during dementia. In line with this hypothesis, we highlight the proinflammatory proteins GFAP and BASP1 which appear as good candidates for further research in this direction. These proteins were identified in this study as containing dementia-specific HCit residues in the particulate brain fraction of dementia subjects. Other proteins identified with exclusive $A D+C V D$ particulate HCit sites are alpha-spectrin, sodium/potassium ATPase, actin 1, V-type proton ATPase 3, and calciumtransporting ATPase 4. Gorisse and colleagues suggested that although HCit-containing proteins should be degraded by common proteolytic mechanisms, some of these proteins seem to show surprising slow turnover rates even when the protein quality control systems in the cells are functional [10]. Similarly, HCit is known to promote endothelial dysfunction and vascular disease [79]; however, uncovering its specific contributions to the pathology of the neurovascular unit in mixed dementias requires of further research.

\section{Conclusions}

Citrullination and carbamylation are involved in the neuropathology of $\mathrm{AD}+\mathrm{CVD}$ through different means. Increase in citrullination involved apparition of exclusive dementia Cit residues in pro-immunogenic proteins, which was associated with pathogenic neuroinflammation. We also observed how proteins prone to contain citrulline residues in the brain proteome of dementia subjects remain soluble whereas these proteins in the brain of age-matched controls tend to be sequestered into aggregates. Protein carbamylation was associated with brain proteinopathy and accumulation of insoluble proteins in the brain parenchyma of $\mathrm{AD}+$ CVD. Altogether, these findings provide relevant and novel insight on the biochemical processes triggered by $\mathrm{uDPMs}$ to contribute to the neuropathology of mixed dementias.

\section{Additional files}

Additional file 1: Table S1. Detail of the human postmortem brain tissues analyzed. (DOC $34 \mathrm{~kb}$ )

Additional file 2: Dataset 1.1: Total group LC-MS/MS peak intensity of the peptides that contain the citrulline triplet in the BA21 brain proteome. (XLS $176 \mathrm{~kb}$ )

Additional file 3: Figure S1. Comparative analysis of soluble and particulate partitioning methodologies by sarcosyl coupled to in-gel digestion and sodium deoxycholate (SDC) coupled to in-solution digestion. a. Number of total proteins identified by LC-MS/MS in the particulate brain 
fractions from both methodologies. b. Number of unique peptides that contain uDPM sites in the LC-MS/MS analyzed particulate brain fractions from both methodologies. (TIFF $212 \mathrm{~kb}$ )

Additional file 4: Dataset 2. List of total proteins identified in the particulate brain fraction of $A D+C V D$ by sarcosyl coupled to in-gel digestion. (XLS $1311 \mathrm{~kb}$ )

Additional file 5: Dataset 3. List of proteins identified in the soluble and particulate brain fractions. (XLS $6489 \mathrm{~kb}$ )

Additional file 6: Dataset 3. List of homocitrulline sites identified in the particulate brain proteomes of AD + CVD. (XLS $68 \mathrm{~kb}$ )

Additional file 7: Dataset 4. Complete list of dementia-specific citrulline sites identified in the soluble brain proteome of AD + CVD. (XLS $82 \mathrm{~kb}$ )

Additional file 8: Dataset 5. List of all identified citrulline sites in the soluble brain proteome of AD + CVD. (XLS 194 kb)

\section{Abbreviations}

AA: Ammonium acetate; ABB: Ammonium bicarbonate; ACN: Acetonitrile; AD + CVD: Alzheimer's disease with cerebrovascular disease; Arg: Arginine; BASP1: Brain acid soluble protein 1; BCA: Bicinchoninic acid assay; CNP: 2',3'Cyclic-nucleotide 3'-phosphodiesterase; DPMs: Degenerative protein modifications; DTT: Dithiothreitol; FA: Formic acid; GFAP: Glial fibrillary acidic protein; His: Histidine; HPLC: High-pressure liquid chromatography; LC-MS/ MS: Liquid chromatography-coupled mass spectrometry; Lys: Lysine; MAC: Membrane attack complex; MBP: Myelin basic protein; P2X7: Purinergic receptor P2X7; PADs: Peptydilarginine deiminases; Pro: Proline;

RA: Rheumatoid arthritis; SDC: Sodium deoxycholate; SPTAN1: Spectrin alpha chain 1; UC-ERLIC: Ultracentrifugation-electrostatic repulsion hydrophilic interaction chromatography-coupled mass spectrometry; uDPMs: Degenerative protein modifications that contain a ureido group

\section{Acknowledgments}

This work was supported by the National Medical Research Council of Singapore (NMRC-OF-IRG-0003-2016), Singapore Ministry of Education (Tier 2: Grant MOE2014-T2-2-043), and NTU-NHG Ageing Research Grant (Grant ARG/ 14017). The Harvard Brain Tissue Resource Center (HBTRC) is supported by a PHS contract and by the HHSN-271-2013-00030C. We thank Louis Fernandes from HBTRC for his kind help and consideration. This study was presented in preliminary form at the symposium P2S2 2016, and the authors thank its acceptance and the comments received. The authors also want to express deep gratitude to the individuals and families that generously made this study possible.

\section{Availability of data and materials}

Proteomics data generated in this study have been made publicly available through the ProteomeXchange consortium via the partner repository PRIDE [80] under the following identifier PXD006233.

\section{Authors' contributions}

XG-P designed the experiments, performed the proteomics, and analyzed the data. AS performed the proteomics and analyzed the data. BSTL analyzed the data. XG performed the proteomics. SKS conceived and supervised the project. $X G-P, A S$, and SKS wrote the paper. All authors have read and approved the final version of the manuscript.

\section{Ethics approval and consent to participate}

Consent authorization for the donation of brain tissues was obtained in all cases. The scientific use of human material in this study was strictly conducted in accordance with the Declaration of Helsinki. All the experimental procedures were approved by the Institutional Review Board of the Nanyang Technological University and were performed according to institutional guidelines.

\section{Consent for publication}

Not applicable.

\section{Competing interests}

The authors declare that they do not have any competing interests regarding the findings reported in this study.

\section{Publisher's Note}

Springer Nature remains neutral with regard to jurisdictional claims in published maps and institutional affiliations.

Received: 2 May 2017 Accepted: 23 August 2017

Published online: 02 September 2017

\section{References}

1. The Lancet N. Dementia warning for the Asia-Pacific region. Lancet Neurol. 2015;14:1.

2. Kalaria RN, Maestre GE, Arizaga R, Friedland RP, Galasko D, Hall K, Luchsinger JA, Ogunniyi A, Perry EK, Potocnik F, et al. Alzheimer's disease and vascular dementia in developing countries: prevalence, management, and risk factors. Lancet Neurol. 2008;7:812-26.

3. Rizzi L, Rosset I, Roriz-Cruz M. Global epidemiology of dementia: Alzheimer's and vascular types. Biomed Res Int. 2014;2014:8.

4. Kalaria R. Similarities between Alzheimer's disease and vascular dementia. J Neurol Sci. 2002;203-204:29-34

5. Ren R-J, Dammer EB, Wang G, Seyfried NT, Levey Al. Proteomics of protein post-translational modifications implicated in neurodegeneration. Transl Neurodegeneration. 2014;3:23.

6. Gallart-Palau X, Serra A, Sze SK. Uncovering neurodegenerative protein modifications via proteomic profiling. Int Rev Neurobiol. 2015;121:87-116.

7. Adav SS, Sze SK. Insight of brain degenerative protein modifications in the pathology of neurodegeneration and dementia by proteomic profiling. Mol Brain. 2016:9:92.

8. György B, Tóth E, Tarcsa E, Falus A, Buzás El. Citrullination: a posttranslational modification in health and disease. Int J Biochem Cell Biol. 2006:38:1662-77.

9. Fando J, Grisolia S. Carbamylation of brain proteins with cyanate in vitro and in vivo. Eur J Biochem. 1974;47:389-96.

10. Gorisse L, Pietrement C, Vuiblet V, Schmelzer CEH, Köhler M, Duca L, Debelle $L$, Fornès $P$, Jaisson $S$, Gillery P. Protein carbamylation is a hallmark of aging. Proc Natl Acad Sci U S A. 2016:113:1191-6.

11. Osaki D, Hiramatsu H. Citrullination and deamidation affect aggregation properties of amyloid beta-proteins. Amyloid. 2016;23:234-41.

12. Shimada N, Handa S, Uchida Y, Fukuda M, Maruyama N, Asaga H, Choi EK, Lee J, Ishigami A. Developmental and age-related changes of peptidylarginine deiminase 2 in the mouse brain. J Neurosci Res. 2010;88:798-806.

13. Witalison EE, Thompson PR, Hofseth L. Protein arginine deiminases and associated citrullination: physiological functions and diseases associated with dysregulation. Curr Drug Targets. 2015;16:700-10.

14. Turunen S, Koivula M-K, Nicholas AP, Risteli L, Risteli J. Homocitrulline: an analog and confounder related to citrulline. In: Nicholas AP, Bhattacharya SK, editors. Protein Deimination in human health and disease. New York: Springer New York; 2014. p. 367-76.

15. Rimon S, Perlmann GE. Carbamylation of pepsinogen and pepsin. J Biol Chem. 1968;243:3566-72

16. Jaisson S, Lorimier S, Ricard-Blum S, Sockalingum GD, Delevallee-Forte C, Kegelaer G, Manfait M, Garnotel R, Gillery P. Impact of carbamylation on type I collagen conformational structure and its ability to activate human polymorphonuclear neutrophils. Chem Biol. 2006;13:149-59.

17. Kalim S, Karumanchi SA, Thadhani RI, Berg AH. Protein carbamylation in kidney disease: pathogenesis and clinical implications. Am J Kidney Dis. 2014;64:793-803.

18. Jang B, Kim E, Choi J-K, Jin J-K, Kim J-I, Ishigami A, Maruyama N, Carp RI, Kim Y-S, Choi E-K. Accumulation of citrullinated proteins by up-regulated peptidylarginine deiminase 2 in brains of scrapie-infected mice: a possible role in pathogenesis. Am J Pathol. 2008;173:1129-42.

19. Carrillo-Vico A, Leech MD, Anderton SM. Contribution of myelin autoantigen citrullination to T cell autoaggression in the central nervous system. J Immunol. 2010;184:2839-46.

20. Moscarello MA, Mastronardi FG, Wood DD. The role of citrullinated proteins suggests a novel mechanism in the pathogenesis of multiple sclerosis. Neurochem Res. 2007;32:251-6.

21. Pruijn GJM. Citrullination and carbamylation in the pathophysiology of rheumatoid arthritis. Front Immunol. 2015:6:192

22. Aguzzi A, Kana V: Protein aggregation in neurodegeneration. In Neurodegeneration: The Molecular Pathology of Dementia and Movement Disorders. Wiley-Blackwell; 2011: 13-17.

23. Treusch S, Cyr DM, Lindquist S. Amyloid deposits: protection against toxic protein species? Cell Cycle. 2009;8:1668-74. 
24. Chen B, Retzlaff M, Roos T, Frydman J. Cellular strategies of protein quality control. Cold Spring Harb Perspect Biol. 2011;3:a004374.

25. Arrasate M, Mitra S, Schweitzer ES, Segal MR, Finkbeiner S. Inclusion body formation reduces levels of mutant huntingtin and the risk of neuronal death. Nature. 2004;431:805-10.

26. Tutar $Y$, Özgür A, Tutar L: Role of protein aggregation in neurodegenerative diseases. 2013.

27. Ishigami A, Maruyama N. Importance of research on peptidylarginine deiminase and citrullinated proteins in age-related disease. Geriatr Gerontol Int. 2010;10(Suppl 1):S53-8.

28. Ishigami A, Ohsawa T, Hiratsuka M, Taguchi H, Kobayashi S, Saito Y, Murayama S, Asaga H, Toda T, Kimura N, Maruyama N. Abnormal accumulation of citrullinated proteins catalyzed by peptidylarginine deiminase in hippocampal extracts from patients with Alzheimer's disease. $J$ Neurosci Res. 2005;80:120-8.

29. Asaga $H$, Ishigami $A$ : $<b>$ Protein Deimination in the rat brain: generation of citrulline-containing proteins in cerebrum perfused with oxygen-deprived $</$ b $>\langle$ b $>$ Media $</$ b $>$. Biomed Res 2000, 21:197-205.

30. Ishigami A, Choi E-K, Kim Y-S, Maruyama N. Deimination in Alzheimer's disease. In: Nicholas AP, Bhattacharya SK, editors. Protein deimination in human health and disease. New York: Springer New York; 2014. p. 237-55.

31. Jin Z, Fu Z, Yang J, Troncosco J, Everett AD, Van Eyk JE. Identification and characterization of citrulline-modified brain proteins by combining HCD and CID fragmentation. Proteomics. 2013;13:2682-91.

32. Turunen S, Koivula MK, Risteli L, Risteli J. Ureido group-specific antibodies are induced in rabbits immunized with citrulline- or homocitrullinecontaining antigens. Autoimmunity. 2016;49:459-65.

33. Larance M, Lamond Al. Multidimensional proteomics for cell biology. Nat Rev Mol Cell Biol. 2015;16:269-80.

34. Hao P, Adav SS, Gallart-Palau X, Sze SK. Recent advances in mass spectrometric analysis of protein deamidation. Mass Spectrom Rev 2016;9999:1-16.

35. Adav SS, Gallart-Palau X, Tan KH, Lim SK, Tam JP, Sze SK. Dementia-linked amyloidosis is associated with brain protein deamidation as revealed by proteomic profiling of human brain tissues. Mol Brain. 2016;9:20.

36. Serra A, Gallart-Palau X, Wei J, Sze SK: Characterization of glutamine deamidation by LERLIC-MS/MS in shotgun proteomics. Anal Chem. 2016;88(21):10573-82.

37. Serra A, Zhu H, Gallart-Palau X, Park JE, Ho HH, Tam JP, Sze SK. Plasma proteome coverage is increased by unique peptide recovery from sodium deoxycholate precipitate. Anal Bioanal Chem. 2016;408:1963-73.

38. Zhang J, Xin L, Shan B, Chen W, Xie M, Yuen D, Zhang W, Zhang Z, Lajoie GA, Ma B. PEAKS DB: de novo sequencing assisted database search for sensitive and accurate peptide identification. Mol Cell Proteomics. 2012;11:M111.010587.

39. Han X, He L, Xin L, Shan B, Ma B. PeaksPTM: mass spectrometry-based identification of peptides with unspecified modifications. J Proteome Res. 2011;10:2930-6.

40. Pathan M, Keerthikumar S, Ang CS, Gangoda L, Quek CY, Williamson NA, Mouradov D, Sieber OM, Simpson RJ, Salim A, et al. FunRich: an open access standalone functional enrichment and interaction network analysis tool. Proteomics. 2015;15:2597-601.

41. Gallart-Palau X, Serra A, Wong AS, Sandin S, Lai MK, Chen CP, Kon OL, Sze SK. Extracellular vesicles are rapidly purified from human plasma by PRotein Organic Solvent PRecipitation (PROSPR). Sci Rep. 2015;5:14664.

42. Greenberg SG, Davies P. A preparation of Alzheimer paired helical filaments that displays distinct tau proteins by polyacrylamide gel electrophoresis. Proc Natl Acad Sci U S A. 1990;87:5827-31.

43. Ren Y, Sahara N. Characteristics of tau oligomers. Front Neurol. 2013;4:102.

44. Ross CA, Poirier MA. What is the role of protein aggregation in neurodegeneration? Nat Rev Mol Cell Biol. 2005;6:891-8.

45. Ayyadevara S, Balasubramaniam M, Parcon PA, Barger SW, Griffin WS, Alla R, Tackett AJ, Mackintosh SG, Petricoin E, Zhou W, Shmookler Reis RJ. Proteins that mediate protein aggregation and cytotoxicity distinguish Alzheimer's hippocampus from normal controls. Aging Cell. 2016;15:924-39.

46. Zhang B, Gaiteri C, Bodea LG, Wang Z, McElwee J, Podtelezhnikov AA, Zhang C, Xie T, Tran L, Dobrin R, et al. Integrated systems approach identifies genetic nodes and networks in late-onset Alzheimer's disease. Cell. 2013;153:707-20.

47. Heneka MT, Carson MJ, El Khoury J, Landreth GE, Brosseron F, Feinstein DL, Jacobs AH, Wyss-Coray T, Vitorica J, Ransohoff RM, et al. Neuroinflammation in Alzheimer's disease. Lancet Neurol. 2015;14:388-405.

48. Rivest $\mathrm{S}$. Regulation of innate immune responses in the brain. Nat Rev Immunol. 2009;9:429-39.
49. Gallart-Palau X, Lee BS, Adav SS, Qian J, Serra A, Park JE, Lai MK, Chen CP, Kalaria RN, Sze SK. Gender differences in white matter pathology and mitochondrial dysfunction in Alzheimer's disease with cerebrovascular disease. Mol Brain. 2016;9:27.

50. Kono H, Rock KL. How dying cells alert the immune system to danger. Nat Rev Immunol. 2008:8:279-89.

51. Atarashi K, Nishimura J, Shima T, Umesaki Y, Yamamoto M, Onoue M, Yagita H, Ishii N, Evans R, Honda K, Takeda K. ATP drives lamina propria T(H)17 cell differentiation. Nature. 2008:455:808-12.

52. Lister MF, Sharkey J, Sawatzky DA, Hodgkiss JP, Davidson DJ, Rossi AG, Finlayson K. The role of the purinergic P2X7 receptor in inflammation. J Inflamm (Lond). 2007:4:5.

53. Shiratori M, Tozaki-Saitoh H, Yoshitake M, Tsuda M, Inoue K. P2X7 receptor activation induces CXCL2 production in microglia through NFAT and PKC/ MAPK pathways. J Neurochem. 2010:114:810-9.

54. Friedle SA, Brautigam VM, Nikodemova M, Wright ML, Watters JJ. The P2X7Egr pathway regulates nucleotide-dependent inflammatory gene expression in microglia. Glia. 2011;59:1-13.

55. Arandjelovic S, McKenney KR, Leming SS, Mowen KA. ATP induces protein arginine deiminase 2-dependent citrullination in mast cells through the P2X7 purinergic receptor. J Immunol. 2012;189:4112-22.

56. Mowen KA, David M. Unconventional post-translational modifications in immunological signaling. Nat Immunol. 2014;15:512-20.

57. Klareskog L, Ronnelid J, Lundberg K, Padyukov L, Alfredsson L. Immunity to citrullinated proteins in rheumatoid arthritis. Annu Rev Immunol. 2008;26:651-75.

58. Catrina Al, Ytterberg AJ, Reynisdottir G, Malmstrom V, Klareskog L. Lungs, joints and immunity against citrullinated proteins in rheumatoid arthritis. Nat Rev Rheumatol. 2014;10:645-53.

59. Barnado A, Crofford $\amalg$, Oates JC. At the bedside: neutrophil extracellular traps (NETs) as targets for biomarkers and therapies in autoimmune diseases. J Leukoc Biol. 2016;99:265-78.

60. Wang Y, Li M, Stadler S, Correll S, Li P, Wang D, Hayama R, Leonelli L, Han H, Grigoryev SA, et al. Histone hypercitrullination mediates chromatin decondensation and neutrophil extracellular trap formation. J Cell Biol. 2009;184:205-13.

61. Birnbaum G, Kotilinek L, Schlievert P, Clark HB, Trotter J, Horvath E, Gao E, Cox $M$, Braun PE. Heat shock proteins and experimental autoimmune encephalomyelitis (EAE): I. Immunization with a peptide of the myelin protein $2^{\prime}, 3^{\prime}$ cyclic nucleotide $3^{\prime}$ phosphodiesterase that is cross-reactive with a heat shock protein alters the course of EAE. J Neurosci Res. 1996;44:381-96.

62. Sasaki K, Bean A, Shah S, Schutten E, Huseby PG, Peters B, Shen ZT, Vanguri V, Liggitt D, Huseby ES. Relapsing-remitting central nervous system autoimmunity mediated by GFAP-specific CD8 T cells. J Immunol. 2014;192:3029-42.

63. Lu XY, Chen XX, Huang LD, Zhu CQ, Gu YY, Ye S. Anti-alpha-internexin autoantibody from neuropsychiatric lupus induce cognitive damage via inhibiting axonal elongation and promote neuron apoptosis. PLoS One. 2010:5:e11124.

64. Norman GL, Yang C-Y, Ostendorff HP, Shums Z, Lim MJ, Wang J, Awad A, Hirschfield GM, Milkiewicz P, Bloch DB, et al. Anti-kelch-like 12 and antihexokinase 1: novel autoantibodies in primary biliary cirrhosis. Liver Int. 2015;35:642-51.

65. Jain MR, Bian S, Liu T, Hu J, Elkabes S, Li H. Altered proteolytic events in experimental autoimmune encephalomyelitis discovered by iTRAQ shotgun proteomics analysis of spinal cord. Proteome Sci. 2009;7:25.

66. Rotzer V, Breit A, Waschke J, Spindler V. Adducin is required for desmosomal cohesion in keratinocytes. J Biol Chem. 2014;289:14925-40.

67. Chiurchiù V, Maccarrone M, Orlacchio A. The role of reticulons in neurodegenerative diseases. NeuroMolecular Med. 2014;16:3-15.

68. Tuzun E, Rossi JE, Karner SF, Centurion AF, Dalmau J. Adenylate kinase 5 autoimmunity in treatment refractory limbic encephalitis. J Neuroimmunol. 2007;186:177-80.

69. Na BR, Kim HR, Piragyte I, Oh HM, Kwon MS, Akber U, Lee HS, Park DS, Song WK, Park ZY, et al. TAGLN2 regulates T cell activation by stabilizing the actin cytoskeleton at the immunological synapse. J Cell Biol. 2015;209:143-62.

70. Chakrabarti S, Kobayashi KS, Flavell RA, Marks CB, Miyake K, Liston DR, Fowler KT, Gorelick FS, Andrews NW. Impaired membrane resealing and autoimmune myositis in synaptotagmin VII-deficient mice. J Cell Biol. 2003; 162:543-9.

71. Bsibsi M, Bairamovic JJ, Vogt MH, van Duijvenvoorden E, Baghat A, PersoonDeen C, Tielen F, Verbeek R, Huitinga I, Ryffel B, et al. The microtubule 
regulator stathmin is an endogenous protein agonist for TLR3. J Immunol. 2010;184:6929-37.

72. Tukaj S, Węgrzyn G. Anti-Hsp90 therapy in autoimmune and inflammatory diseases: a review of preclinical studies. Cell Stress Chaperones. 2016;21:213-8.

73. Hung CC, Lin $C H$, Chang H, Wang CY, Lin SH, Hsu PC, Sun YY, Lin TN, Shie FS, Kao LS, et al. Astrocytic GAP43 induced by the TLR4/NF-kappaB/STAT3 axis attenuates astrogliosis-mediated microglial activation and neurotoxicity. J Neurosci. 2016;36:2027-43.

74. Zierath D, Kunze A, Fecteau L, Becker K. Promiscuity of autoimmune responses to MBP after stroke. J Neuroimmunol. 2015;285:101-5.

75. Labrador-Horrillo M, Martinez MA, Selva-O'Callaghan A, Trallero-Araguas E, Grau-Junyent JM, Vilardell-Tarres M, Juarez C. Identification of a novel myositis-associated antibody directed against cortactin. Autoimmun Rev. 2014;13:1008-12.

76. Reed E, Jiang X, Kharlamova N, Ytterberg AJ, Catrina Al, Israelsson L, Mathsson-Alm L, Hansson M, Alfredsson L, Ronnelid J, Lundberg K. Antibodies to carbamylated alpha-enolase epitopes in rheumatoid arthritis also bind citrullinated epitopes and are largely indistinct from anticitrullinated protein antibodies. Arthritis Res Ther. 2016;18:96.

77. Mydel P, Wang Z, Brisslert M, Hellvard A, Dahlberg LE, Hazen SL, Bokarewa M. Carbamylation-dependent activation of T cells: a novel mechanism in the pathogenesis of autoimmune arthritis. J Immunol. 2010;

78. Currais A, Fischer W, Maher P, Schubert D. Intraneuronal protein aggregation as a trigger for inflammation and neurodegeneration in the aging brain. FASEB J. 2017;31:5-10.

79. Speer T, Owala FO, Holy EW, Zewinger S, Frenzel FL, Stähli BE, Razavi M, Triem S, Cvija H, Rohrer L, et al. Carbamylated low-density lipoprotein induces endothelial dysfunction. Eur Heart J. 2014;35:3021-32.

80. Vizcaino JA, Csordas A, Del-Toro N, Dianes JA, Griss J, Lavidas I, Mayer G, Perez-Riverol Y, Reisinger F, Ternent T, et al. 2016 update of the PRIDE database and its related tools. Nucleic Acids Res. 2016;44:11033.

\section{Submit your next manuscript to BioMed Central and we will help you at every step:}

- We accept pre-submission inquiries

- Our selector tool helps you to find the most relevant journal

- We provide round the clock customer support

- Convenient online submission

- Thorough peer review

- Inclusion in PubMed and all major indexing services

- Maximum visibility for your research

Submit your manuscript at www.biomedcentral.com/submit 